\title{
Mouth and throat cancers from HPV on rise in men
}

I n February, after returning home to Calgary from a family vacation in Mexico, Will Dove and his wife both came down with symptoms of ear infections.

"She had an ear infection," said Dove. "I had cancer."

Specifically, Dove had throat cancer caused by a human papillomavirus (HPV) infection. For Dove, the treatment that followed was excruciating. A self-described fitness fanatic, the 51-year-old lost 30 pounds of muscle while undergoing chemotherapy and radiation treatment. On a good day, he could force down 500 calories of food; many days he ate nothing — his throat so sore that even drinking water became impossible. Then there was the constant nausea, the fits of coughing, the mouth sores, the sleepless nights.

"Treatment for HPV throat cancer is hell," said Dove, who completed his treatment 10 weeks ago and is now in recovery. "Words don't even come close to describing it. You cannot understand the misery and suffering you will go through."

Unfortunately, there are many men who may have to go through the same ordeal. The number of men in Canada getting throat and mouth cancer from HPV infections has risen dramatically. Between 1992 and 2012, there has been a $56 \%$ increase in males, compared to $17 \%$ in females, according to Canadian Cancer Statistics 2016, a new report released by the Canadian Cancer Society. Overall, mouth and throat cancers account for a third of all HPV cancers, about the same as cervical cancer. An estimated 4400 Canadians will be diagnosed with an HPV cancer this year, according to the report, and one-third will be male.

The Canadian Cancer Society is urging Canadians to get the HPV vaccine. It is also calling for the expansion of free access to the vaccine for school-aged boys. Currently, it is

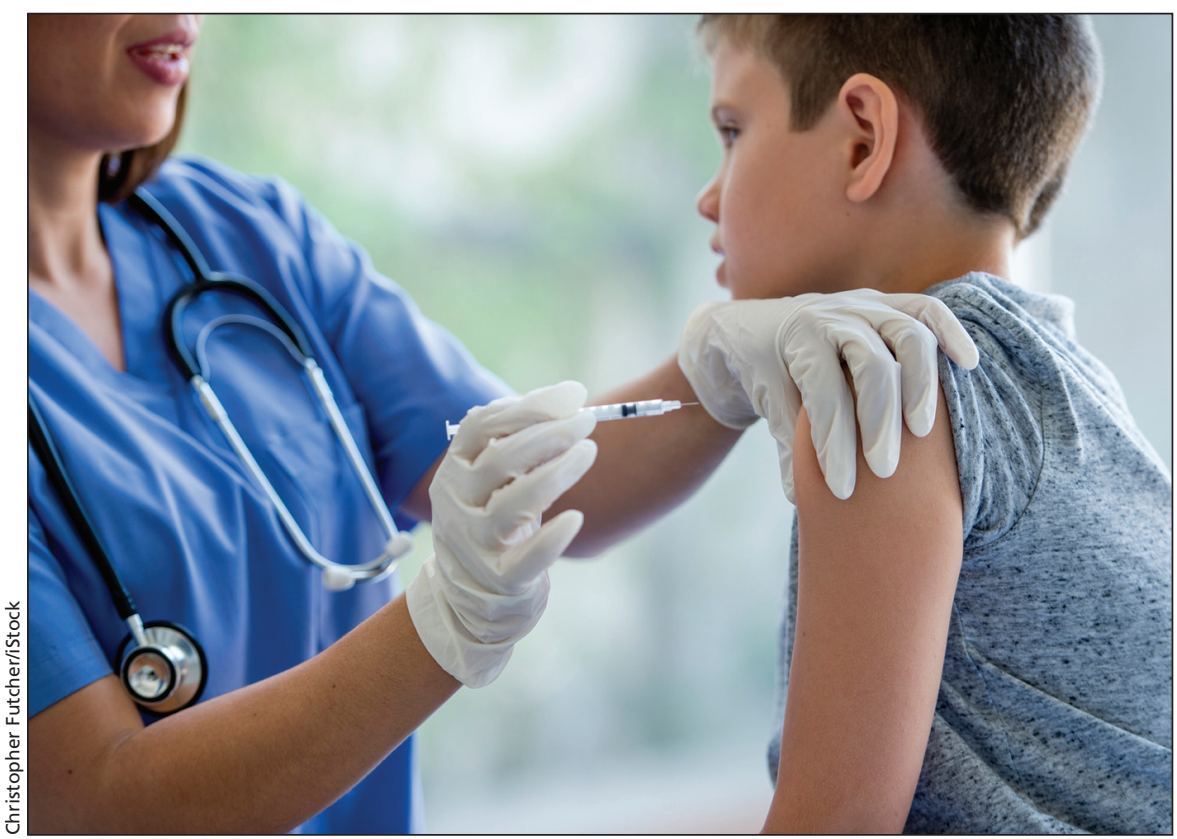

Only six provinces have HPV vaccination programs for boys.

available to girls across Canada but to boys in only six provinces: Alberta, Manitoba, Nova Scotia, Ontario, Prince Edward Island and Quebec.

"I think there are a lot of misconceptions about HPV vaccination," said Leah Smith, an epidemiologist with the Canadian Cancer Society. "One of our goals with this report is to highlight some of the statistics that have never before been available on the impact HPV is having on cancer in Canada."

Smith notes that the HPV vaccine has been studied for more than 20 years and approved for use for more than a decade. It has been shown to be safe and effective all over the world, and the benefits far outweigh the risks.

"One thing that is unique about the HPV vaccine is that most cancerprevention strategies require a lifelong effort in order to reap the benefits, whereas HPV vaccination is relatively easy."

Still, myths about the vaccine persist, which may explain why coverage rates across the country range from $43 \%$ to $91 \%$. The hesitancy of some people to have their children vaccinated can be attributed, in part, to anti-vaccination activism and the media, which often gives them equal voice to that of scientists, according to Dr. Eduardo Franco, chairman of the Department of Oncology at McGill University.

"It's a very tough battle to win," said Franco. "In a way I blame the media for that, with this obsessive need for balance, which they say is part of their ethics. They talk to the scientists, who talk about the evidence, and then they say, for balance, let's go to an activist."

And these activists are "experts in identifying the infinitesimal proportion of cases" that can be linked to vaccine harm, said Franco. Anti-vaccination activists also come armed with emotionally charged stories of children who have suffered, whether or not the harm was actually caused by vaccines. Prevention of disease, on the other hand, tends to make for far less compelling anecdotes.

"We can never depict the side of protection - which is overwhelmingly 
more important, even if we assume there are adverse events, which disappear next to the benefits of vaccination - the same way, because what we can never do, on the side of defending, is say here is a case of a disease that never existed."

For Will Dove, however, there is one story that he will never forget. When he told his 12-year-old son that he had throat cancer, Dove noticed the look of concern on his son's face. Though Dove still had a tough road ahead, he could at least reassure his son that, because he had been vaccinated, his future would likely be free of an HPV-related cancer.

"I will never forget the look of relief on his face," said Dove. "My son will never go through what I went through." - Roger Collier, CMAJ

CMAJ 2016. DOI:10.1503/cmaj.109-5347 